REVIEW

\title{
The role of enterovirus in chronic fatigue syndrome
}

\section{J K S Chia}

J Clin Pathol 2005;58:1126-1132. doi: 10.1136/icp.2004.020255

Two and a half decades after coining of the term chronic fatigue syndrome (CFS), the diagnosis of this illness is still symptom based and the aetiology remains elusive. Enteroviruses are well known causes of acute respiratory and gastrointestinal infections, with tropism for the central nervous system, muscles, and heart. Initial reports of chronic enteroviral infections causing debilitating symptoms in patients with CFS were met with skeptism, and had been largely forgotten for the past decade. Observations from in vitro experiments and from animal models clearly established a state of chronic persistence through the formation of double stranded RNA, similar to findings reported in muscle biopsies of patients with CFS. Recent evidence not only confirmed the earlier studies, but also clarified the pathogenic role of viral RNA through antiviral treatment. This review summarises the available experimental and clinical evidence that supports the role of enterovirus in chronic fatigue syndrome.

Correspondence to:

Dr J K S Chia, CEI

Research Center, 23560

Crenshaw Blvd 101,

Torrance, CA 90505

USA; Chiasann@pol.net

Accepted for publication 14 March 2005

Our recent data suggest that chronic fatigue syndrome is a heterogeneous disease, and can have several potentially treatable infectious aetiologies, as reported previously"

A severe flu-like illness that occurred in most fatigue suggests an infectious aetiology that triggers and possibly perpetuates this syndrome. In small subsets of patients, Epstein-Barr virus, cytomegalovirus, parvovirus B19, brucella, toxoplasma, Coxiella burnetti, and Chlamydia pneumoniae have been reported to cause prolonged fatigue, fevers, and many other symptoms of CFS. $^{3-8}$ Other viruses have been investigated as the causative agents of CFS: human herpesvirus 6 (HHV-6), group B coxsackieviruses (CVB), human $\mathrm{T}$ cell leukaemia virus II-like virus, spumavirus, hepatitis $\mathrm{C}$ virus, human lentiviruses, and herpesvirus 7 , although consistent and compelling supportive evidence is still lacking. Komaroff et al view CFS as an immunological disturbance that allows the reactivation of latent and persistent infectious agents, particularly viruses, in the host. ${ }^{3}$ Levy believes that although no viral agents have been found consistently in patients with CFS, an infectious organism may be the cause of this condition and may continue to be present in the individual. ${ }^{4}$ Our recent data suggest that CFS is a heterogeneous disease, and can have several potentially treatable infectious aetiologies, as reported previously. ${ }^{9}$

\section{EVIDENCE FOR ENTEROVIRUS INFECTION IN CFS}

The role of enteroviruses as the causative agents of CFS has been controversial. In one study, evidence of circulating enteroviral antigen and IgM complexes was found in most patients with CFS. ${ }^{10}$ Landay et al found a high seroprevalence of CVB among patients with CFS. ${ }^{11}$ However, Miller et al and others detected no differences between the IgM and IgG seroprevalence rates for these viruses between patients with CFS and controls. ${ }^{12-15}$ These studies used a variety of criteria to select patients with CFS and were carried out at different time points and in different locations. It is possible that different conclusions have been drawn because Coxsackievirus epidemiology varies with time and place. ${ }^{16}$

Several investigators used DNA/RNA hybridisation or polymerase chain reaction (PCR) to detect the presence of enteroviral RNA in tissues of patients with CFS. ${ }^{17-22}$ Nairn et al found PCR superior to neutralising antibody for differentiating patients with CFS from controls. ${ }^{17}$ Using PCR, Gow et al found enteroviral RNA sequences in $53 \%$ of muscle biopsy specimens taken from patients with CFS, which was significantly cases of CFS followed by persistent illness and
Abbreviations: CFS, chronic fatigue syndrome; CVB, group B coxsackievirus; HHV-6, human herpesvirus 6; PBMC, peripheral blood mononuclear cells; PCR, polymerase chain reaction; RT, reverse transcription 
higher than those of normal controls. ${ }^{19}$ A subsequent study by the same authors examining the presence of RNA in muscle biopsies taken from patients with CFS or controls with neuromuscular disorders detected enteroviral RNA in $26.4 \%$ of patients with CFS and $19.8 \%$ of controls. Therefore, they concluded that persistent enterovirus infection is unlikely to play a pathogenic role in CFS, although an effect on initiating the disease process could not be excluded. ${ }^{20}$ Muscle biopsies also showed little evidence of necrosis or inflammation suggesting that the virus, if present, was at very low copy numbers, not enough to produce lytic infection or noticeable inflammation. However, patients with chronic neuromuscular diseases are not as active as normal people, and the highly sensitive albeit qualitative RNA PCR test could not compare the amounts of RNA in tissue specimens of the two groups. Mechanistically, the metabolic activity of infected muscle cells could be an important determinant of viral RNA replication and the ensuing immunological response causing post-exertion fatigue.

Youseff et al reported CVB RNA persistence in muscle fibres in six of 13 adult patients with dermatomyositis or polymyositis using in situ hybridisation. ${ }^{21}$ The enteroviral RNA was usually, but not always, found in sections with inflammatory cells. Cunningham et al tested muscle biopsy specimens from patients with CFS and showed that the enteroviral RNA found in patient material had a positive to negative strain ratio of $1: 1$, rather than the $100: 1$ ratio found in control enteroviral cultures. ${ }^{22}$ This result suggested a defect in control of enteroviral RNA synthesis in patients with CFS that might permit persistence of the defective virus in these patients. Galbraith et al extended the above finding by performing phylogenetic analysis of the amplified cDNA from the blood of patients; the sequences closely matched those found in CVB and echoviruses. ${ }^{23}$ Several other studies have failed to demonstrate amplifiable enteroviral RNA in blood or in other tissue, ${ }^{24} 25$ although two recent papers again demonstrated the presence of enteroviral RNA in muscle biopsies of patients with CFS and not in the controls. ${ }^{26}{ }^{27}$ The discrepancy between the various studies is not well explained, but could result from differences in specimen collection and RNA preservation, the time to processing of the biopsies or blood samples, the primers used, and the sensitivity of the assay.

\section{IN VITRO VIRAL PERSISTENCE}

In vitro observation has lent support for mechanisms of viral persistence. Lytic viruses can persist in vitro under conditions where only a small fraction of the total cells is infected at any one time. $.^{28-30} \mathrm{CaCo}-2$ cells, an intestinal cell line, were shown to develop a persistent infection for up to 20 passages, as demonstrated by the detection of viral RNA and VPl protein. ${ }^{31}$ CVB can persistently infect endothelial cell cultures without producing overt cytopathic effects. Infected endothelial cells retained endothelial characteristics but infection upregulated expression of adhesion molecules and led to increased production of the proinflammatory cytokines, interleukin 6, interleukin 8, and tumour necrosis factor $\alpha^{32}$ Yin showed that certain strains of CVB4 can infect pancreatic islet cells without immediate cytotoxicity, and the gradual loss of islet cell function over months was not caused by virus induced changes in cell morphology, although virus-like particles were seen at higher magnification. ${ }^{33}$ Brilot et al demonstrated persistent replication of CVB4 strains in thymic epithelial cell cultures by detection of positive and negative strand viral RNA in cell culture extracts, VPI capsid protein detection by immunofluorescence staining, and release of infectious particles up to 30 days after infection without obvious cytolysis. ${ }^{34}$ Furthermore, Feuer et al elegantly demonstrated in HeLa cells that cell cycle status determines the distribution of CVB3 during acute infection, and the persistence of CVB3 in vivo might rely on the infection of quiescent cells incapable of supporting viral replication. A subsequent change in the cell cycle status could lead to virus reactivation, triggering chronic viral and/or immune mediated pathology in the host. ${ }^{35}$ Some enteroviruses are known to infect peripheral mononuclear cells, which often harbour various intracellular pathogens. ${ }^{36} 37$

\section{EVIDENCE OF CHRONIC ENTEROVIRUS INFECTION IN ANIMAL MODELS}

The mouse model of viral myositis and myocarditis has shed much light on the pathogenesis of Coxsackie virus infection and provides a logical paradigm for patients with CFS. To cite just a few studies, Tam and Messner found persistence of CVB RNA, in a stable, double stranded form, made of equal amounts of plus and minus strands, but not culturable virion, in various tissues of mice for as long as one year after initial infection, similar to findings on thigh muscle biopsies in patients with CFS. ${ }^{38}$ In a murine myocarditis model, Reetoo et al demonstrated a biphasic pattern of virus clearance. Initially, there was a rapid but incomplete clearance of viral RNA from the myocardium after the acute phase of virus replication, which paralleled the elimination of virus infectivity. Viral RNA persisted in the myocardium beyond the resolution of inflammation and was still detectable in a proportion of animals 90 days after infection. Clearance of viral RNA from other target organs occurred more rapidly, but the rate of clearance was largely independent of the amount of viral RNA present during the acute phase of infection. The authors concluded that, although antiviral immune responses effectively eliminated infectious virus, clearance of residual viral RNA from the myocardium and other target organs was significantly delayed, despite a prolonged inflammatory response. These findings suggest that the clearance of persistent enterovirus infection requires mechanisms different from those responsible for the elimination of virus infectivity. ${ }^{39}$ In addition, Klingel et al showed in a murine model of enterovirus myocarditis that enterovirus is capable of inducing multiorgan disease. During acute infection, large amounts of viral RNA were visualised in the heart muscle, pancreas, spleen, and lymph nodes and in low amounts in the central nervous system, thymus, lung, and liver. At later stages of the disease, the presence of enteroviral RNA was found to be restricted to the myocardium, spleen, and lymph nodes. ${ }^{40}$ Detection of the replicative minus strand RNA intermediate provided evidence for virus replication in lymphoid cells of the spleen, predominantly $\mathrm{B}$ cells, certain CD4+ helper T cells, and tissue macrophages.

\section{RENEWED INTEREST IN FINDING ENTEROVIRUS INFECTIONS IN CFS}

Despite previous negative studies, published or unpublished, from the USA on the infectious aetiology of CFS, ${ }^{41}$ it is difficult to ignore the possibility of "smouldering infections" as the basis for this illness when patients consistently complain of continuing or cycling viral symptoms, some of which are the defining criteria for this elusive disorder. ${ }^{1}$ During our study to determine the infectious aetiology in the first 200 patients with severe fatigue following flu-like illnesses, several commonly encountered infectious agents and unusual causes were diagnosed based on the details of the initial flu-like illness, if present, and epidemiological factors, critical reviewing of previous medical records and laboratory tests, repeated serological testing for enteroviruses, hepatitis viruses, Chlamydia pneumoniae, whole blood DNA testing for Epstein-Barr virus, HHV-6, and cytomegalovirus, and a convincing response to specific anti-infective treatment. ${ }^{9}$ Rare patients had initial symptoms of infection 
and laboratory tests suggestive of acute Epstein-Barr virus, cytomegalovirus, or HHV-6 infection. Significantly raised neutralising antibody titres against six coxsackieviruses or five echoviruses were found in more than half of those patients who had initial respiratory and/or gastrointestinal tract infections, compared with 150 control subjects, consisting of patient's spouses or relatives and patients who visited the clinic on the same day for general medical conditions or other known infectious diseases not associated with fatigue. These antibody concentrations in patients with CFS were still raised more than 48 months after this observation.

\section{"Despite previous negative studies on the infectious aetiology of chronic fatigue syndrome, it is difficult to ignore the possibility of smouldering infections as the basis for this illness when patients consistently complain of continuing or cycling viral symptoms"}

However, the presence of high concentrations of neutralising antibody to enterovirus may only imply adequate humoral immunity to enterovirus. We looked for the presence of enteroviral RNA in the plasma and in the peripheral blood mononuclear cells (PBMC) of patients who had high titres of neutralising antibody to enteroviruses and/ or raised creatine phosphokinase. Using a nested reverse transcription (RT) PCR protocol with primers from the highly conserved 5' non-translated region, enteroviral RNA was detected in the PBMC of 16 of 23 seropositive patients and in none of the four controls; only two of 23 patients had detectable RNA in the plasma, although blood specimens were not processed for about 18 hours after collection. Three of the randomly selected samples of amplified cDNA were confirmed to be an enterovirus sequence. ${ }^{42}$

A second laboratory also confirmed enteroviral RNA in the plasma/PBMC of patients using different primers and amplification conditions. ${ }^{42}$ Four of 23 seropositive patients with CFS showed detectable RNA in the plasma; six of 22 PBMC specimens were positive, although the white cells were not harvested until 48 hours after phlebotomy. The sequences of four samples closely resembled that of coxsackievirus (97$99 \%$ ), although some differences existed among the different cDNA samples. Three patients with strongly positive enteroviral RNA in their PBMC had no detectable neutralising antibody to the 11 enteroviruses tested, which suggested that infections could be caused by the other echoviruses or enteroviruses not identified by commercially available neutralising antibody tests.

Our laboratory extended these findings to a larger cohort of patients with CFS using a rapid, RT-PCR protocol, which used biotinylated primer and probe hybridisation. Blood specimens were processed within two to four hours of phlebotomy to avoid RNAse degradation, ${ }^{43}$ because pilot experiments showed decrease yield when the blood samples were stored for more than six hours. Initially, amplified enteroviral RNA was found in 112 of $236(48 \%)$ patients with CFS and nine of $118(8 \%)$ controls ( $\mathrm{J}$ Chia and A Chia. Detection of enteroviral RNA in the peripheral blood leukocytes of patients with the chronic fatigue syndrome. Abstract 763. In: Program and abstracts of the $40^{\text {th }}$ annual meeting of the Infectious Diseases Society of America. Chicago: Illinois. IDSA, 2002:178); 50 of 131 (38\%) patients with CFS and two of 52 controls tested positive on two or more occasions $\left(\mathrm{p}<0.001 ; \chi^{2}\right.$ test $)$. On serial testing of blood samples, 14 of the 20 most severely affected patients tested positive twice or more, compared with 10 of 80 patients who could work 20-40 hours a week (J Chia and A Chia. Detection of doublestranded RNA in the peripheral blood leukocytes of patients with the chronic fatigue syndrome. Abstract T-101. In:
Program of the $104^{\text {th }}$ General Meeting for the American Society of Microbiology. New Orleans: Louisiana, 2004). In five of the severely ill patients more than $80 \%$ of their samples tested positive; and two patients were positive in all samples (table 1). Two patients with extremely high antibody titres to CVB had detectable enteroviral RNA in only one of multiple samples. The reproducibility of the RT-PCR assay was variable, although a detection threshold of 80-800 copies/ml, using an enterovirus RNA standard, was achievable in most of the runs. To date, cell associated enteroviral RNA has been found in about $35 \%$ of 518 patients.

RT-PCR was repeated on 20 strongly positive enteroviral RNA samples with and without prior RNAse l digestion. RNAse 1 digestion did not affect the amplification of the RNA samples, although a single stranded enteroviral RNA standard was degraded by the enzyme ( $\mathrm{J}$ Chia and A Chia. Detection of double-stranded RNA in the peripheral blood leukocytes of patients with the chronic fatigue syndrome. Abstract T-101. In: Program of the $104^{\text {th }}$ General Meeting for the American Society of Microbiology. New Orleans: Louisiana, 2004). This preliminary evidence suggested that the enteroviral RNA found in peripheral blood leucocytes might be double stranded, at least in the region of amplification. This finding from peripheral leucocytes confirmed the previous data on the presence of double stranded RNA in muscle biopsies of patients with CFS and in chronically infected mice..$^{22} 38$

\section{EVIDENCE FROM ANTIVIRAL TREATMENT}

Even though the above data confirmed the observations of others, ${ }^{17-23}$ the importance of enteroviral RNA in human disease remains undefined. The results of antiviral treatment provided supportive evidence for the pathogenic role of RNA in patients with CFS. Interferon and Ribavirin were effective against CVB in carrier cultures and in a murine model of myocarditis. ${ }^{44-46}$ Two previous, small studies have demonstrated the efficacy of interferon in patients with CFS, but the follow up was only three months and virological studies were not done. ${ }^{47}{ }^{48}$ Ten of our most symptomatic patients who had persistently high titres of neutralising antibody for CVB3 or CVB5 ( $\geqslant 1: 640$ ) were treated with Ribavirin $400 \mathrm{mg}$ twice daily for four months. Seven patients had a significant improvement of fatigue and other flu-like symptoms while on Ribavirin, but relapsed one to two weeks after discontinuation. All seven patients had a fourfold or greater reduction of neutralising antibody while on treatment, but the values increased post-treatment when the patients relapsed. Enteroviral RNA was found in the PBMC of all seven patients and in two consecutive specimens for two of three patients, obtained two weeks apart, before the start of the interferon $\alpha$ and Ribavirin treatment. Enteroviral RNA became negative two to four weeks after the start of treatment. Fatigue did not improve during treatment probably because of the side effects of the interferon. After discontinuation of treatment, the patients felt much better for two to four months and antibody titres decreased and remained at $\leqslant 1: 80$. However, relapse occurred in four patients about four to five months post-treatment; the antibody titre increased to pretreatment values in all four patients and the enteroviral RNA became positive at least once in all of the patients who relapsed. ${ }^{49}$

\section{"The results of antiviral treatment provided supportive evidence for the pathogenic role of RNA in patients with chronic fatigue syndrome"}

Interferon $\alpha$ and $\delta$ have pronounced synergistic activity against enterovirus. ${ }^{50}$ One bedridden patient with detectable enteroviral RNA in the blood on multiple occasions, 


\begin{tabular}{|c|c|c|c|c|c|c|c|c|c|c|}
\hline \multirow[t]{2}{*}{ Patient identifier } & \multirow[t]{2}{*}{ Duration of illness (years) } & \multicolumn{9}{|c|}{ Month } \\
\hline & & 1 & 3 & 6 & 9 & 12 & 15 & 18 & 21 & 24 \\
\hline$B C$ & 5 & ++ & & ++ & & - & & - & & ++ \\
\hline BS & 3 & ++ & ++ & & & - & & & & \\
\hline$B M$ & 4 & ++ & & + & + & + & & & + & + \\
\hline BA & 2 & ++ & - & + & & & \pm & & - & - \\
\hline BJ & 2 & + & - & & \pm & & & & + & \\
\hline $\mathrm{CL}$ & 20 & ++ & & - & \pm & + & - & & & \\
\hline DP & 14 & + & - & - & & - & & - & & - \\
\hline $\mathrm{GL}$ & 10 & ++ & & - & - & & - & & & \\
\hline $\mathrm{GH}$ & 10 & ++ & H & & \pm & - & + & & \pm & - \\
\hline $\mathrm{GA}$ & 8 & - & + & & + & ++ & & & & \\
\hline GK & 3 & ++ & - & - & & - & & - & & ++ \\
\hline$G B$ & 11 & + & H & & - & & & \pm & & - \\
\hline$G C$ & 2 & ++ & + & - & - & - & & + & & \\
\hline HK & 10 & + & + & - & & + & - & & & - \\
\hline HG & 5 & ++ & - & & 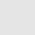 & \pm & - & + & & - \\
\hline $\mathrm{HL}$ & 3 & + & + & + & & + & \pm & - & - & \\
\hline KT & 1 & ++ & + & + & & + & & & & \\
\hline MP & 1 & + & + & + & & - & \pm & & - & - \\
\hline$M B$ & 7 & ++ & - & - & & + & - & & & . \\
\hline PK & 2 & + & + & & - & & & - & & - \\
\hline
\end{tabular}

All of the patients were bedridden most of the time. Energy indices ${ }^{5}$ were consistently less than 2 on a 0-10 scale. The enteroviral RNA reverse transcription polymerase chain reaction/enzyme linked immunosorbent assay was performed as described previously. ${ }^{49}$ The final optical density (OD) was measured and tabulated.,$++ \mathrm{OD}$ of 2 to $\geqslant 3 ;+1-1.9 ; \pm, 0.5-0.99 ;-, \leqslant 0.49$. The negative control was consistently $\leqslant 0.49$.

CSF, chronic fatigue syndrome; PBL, peripheral blood leucocytes.

confirmed by sequencing ( $\mathrm{J}$ Chia and A Chia. Detection of enteroviral RNA in the peripheral blood leukocytes of patients with the chronic fatigue syndrome. Abstract 763 . In: Program and abstracts of the $40^{\text {th }}$ annual meeting of the Infectious Diseases Society of America. Chicago: Illinois. IDSA, 2002:178), ${ }^{42}$ was treated with a combination of 3 million units interferon $\alpha$ and 2 million units interferon $\gamma$, three times a week. The patient recorded her biweekly energy index before, during, and after interferon treatment (fig 1A). The patient returned to full time work two months after the treatment was completed. Enteroviral RNA remained negative until she had a transient symptomatic and virological relapse after vigorous exercise. Remission lasted about 14 months before the symptoms returned to the pretreatment baseline. The patient responded to an additional course of interferon treatment. A second patient had a similar symptomatic response along with a virological response and relapse with this combination treatment (fig $1 \mathrm{~B}$ ). To date, eight of 14 severely ill patients with detectable enteroviral RNA in their peripheral blood leucocytes have responded to the combination of interferon $\alpha$ and $\delta$; six of the 11 totally disabled patients returned to work on a half time or full time basis, but relapse still occurred in most patients after heavy exertion a few months later. No commercial funding is currently available for a placebo controlled study.

\section{"To date, eight of 14 severely ill patients with detectable enteroviral RNA in their peripheral blood leucocytes have responded to the combination of interferon $\alpha$ and $\delta^{\prime \prime}$}

Four patients with CFS and either persistently raised antibody titres for CVB or echoviruses and/or positive enteroviral RNA of the peripheral blood leucocytes were treated with Pleconaril, an anti-capsid agent specific for uncoating of enterovirus and rhinovirus, obtained through a compassionate use protocol of Viropharma Inc, Exton, Pennsylvania, USA. Three patients had no symptomatic improvement while on or after one week of drug treatment, at a dose of $400 \mathrm{mg}$ three times a day, and there was no change of antibody titre after the treatment. One patient had a moderate symptomatic improvement while taking
Pleconaril $200 \mathrm{mg}$ three times a day for one month, along with a fourfold decrease of antibody titres for CVB4 and echoviruses 7 and 11. However, she relapsed about one month later, and did not respond to a further month of treatment. As of March 2004, the oral form of Pleconaril is no longer available for investigational use.

\section{DISCUSSION}

Taken together, these data suggest that enterovirus can initiate and perpetuate the immunological response often seen in patients with CFS. Smouldering viral infection of various cells of the body with continuous expression of double stranded RNA and viral antigens could result in a chronic inflammatory state in the local tissues and account for the diverse symptoms reported by these patients.

The mechanism of viral persistence reconciles the two seemingly opposing observations of the past two decades: absence of live virion in chronically infected patients and animals and the finding of enteroviral RNA in the blood or other tissues. The finding of double stranded RNA is consistent with the clinical symptoms of patients with CFS. Without forming double stranded RNA, our patients with HIV or hepatitis B/C infections are usually not symptomatic, even though the measurable viraemia often exceeds $10^{4}-10^{6} \%$ $\mathrm{ml}$. In contrast, patients with CFS and the presence of viral RNA in peripheral blood leucocytes or in tissues, but without true viraemia, have debilitating symptoms; the severity of the symptoms correlated with the frequency of finding enteroviral RNA in the peripheral blood leucocytes ( $\mathrm{J}$ Chia and A Chia. Detection of double-stranded RNA in the peripheral blood leukocytes of patients with the chronic fatigue syndrome. Abstract T-101. In: Program of the $104^{\text {th }}$ General Meeting for the American Society of Microbiology. New Orleans: Louisiana, 2004). In most of the patients with CFS, the cyclic nature of low grade febrile illness and severe exacerbation after physical activity would be consistent with a cyclical pattern in the viral replicative activity.

It is probable that viral RNA found inside cells, in a stable double stranded form, can dissociate and replicate using viral RNA replicase; some of the positive strands, although restricted in replication, ${ }^{51}$ are translated to viral proteins during active metabolic states (for instance, exercise), which subsequently 
A

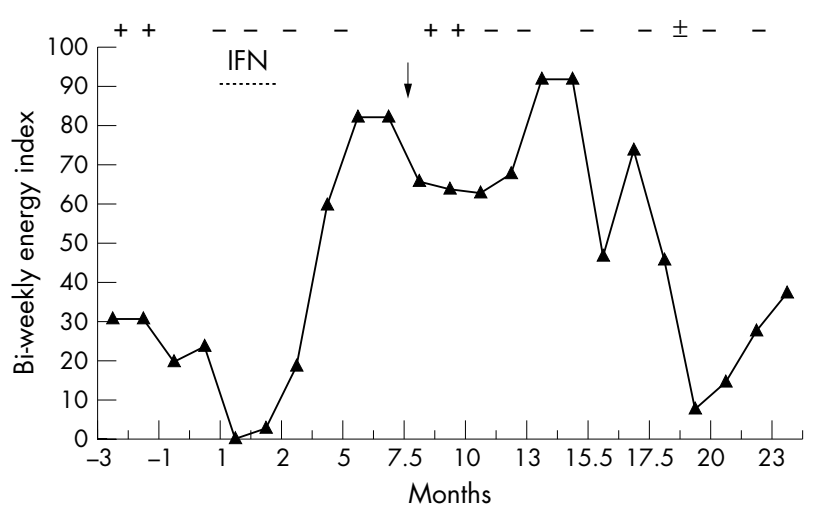

$B$

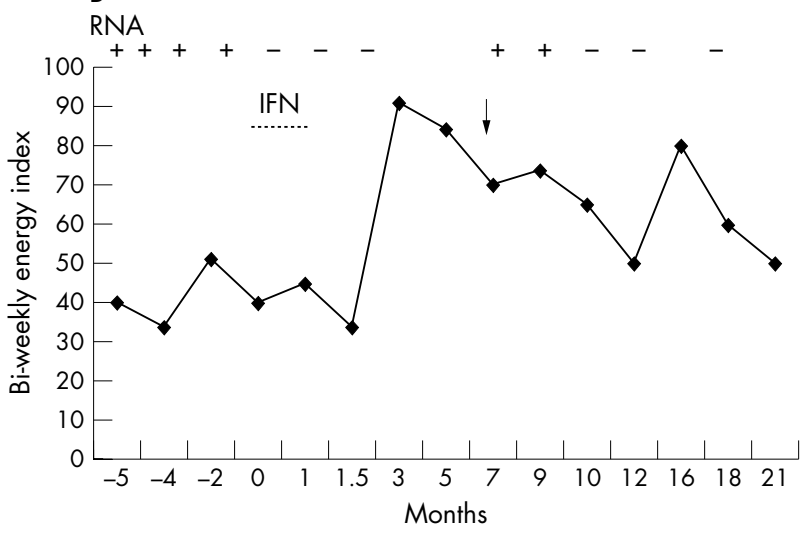

Figure 1 Clinical and virological response to combination treatment with interferon $\alpha$ and interferon $\gamma$. Biweekly energy level, the sum of daily energy index (0-10) for two weeks, was recorded by two patients (A, B) before, during, and after a one month treatment with interferon $\alpha$ (Pegasys $180 \mu \mathrm{g}$; once/week) and interferon $\gamma$ (100 $\mu \mathrm{g}$; three times/ week). An enteroviral RNA assay of the peripheral blood leucocytes were performed before, during, and after the treatment, and expressed as + or - on the top of the graph. The arrow indicates vigorous exercise after treatment. The graphs show clearance of circulating viral RNA after antiviral treatment, and an association between vigorous exercise, reappearance of circulating viral RNA, and decreased energy.

perpetuates the immunological response, including but not limited to synthesis of specific neutralising antibody. Consistent with this hypothesis, a recent study on Sjögren's syndrome clearly detected enteroviral RNA and VPI protein in minor salivary gland biopsies from these patients, but not in controls. ${ }^{52}$ From the available data in the literature, however, it is not possible to exclude with complete certainty the possibility that a few virions are actually formed and sequestered in membrane vesicles within the infected human cells.

Among other immunostimulatory effects, double stranded RNA is a potent inducer of interferon synthesis, which activates intracellular RNase, with resultant degradation of excessive single stranded RNA. The finding of a higher level of RNase L activity in the mononuclear cells of patients with CFS is consistent with this paradigm. ${ }^{53}{ }^{54}$ However, enough positive and negative strands probably recombine to form stable double stranded RNAs, which are resistant to RNAse L inactivation, and the life cycle will start again when the pressure of the immune response decreases. Ironically, the continuing inflammatory response towards persistently infected cells/tissues to halt viral infection may be partially responsible for the difficulty in finding viral genomes in these patients, and may also be responsible for the symptoms.
Take home messages

- A severe flu-like illness occurs in most cases of chronic fatigue syndrome (CFS), suggesting that an infection triggers and possibly perpetuates this syndrome

- Common viral infections and unusual causes of CFS could be diagnosed based on the details of the initial flu-like illness, if present, epidemiological history, and early virological testing

- Different laboratories from Europe and recently from the USA have found enteroviral RNA in the tissues, including peripheral blood mononuclear cells and muscles, of patients with CFS

- Viral persistence through the formation of stable double stranded RNA reconciles the two opposing observations of the past two decades: (1) the absence of live virion in chronically infected patients and animals and (2) the presence of enteroviral RNA in the blood or other tissues

- Smouldering viral infection of various cells with continuous expression of double stranded RNA and viral antigens could result in a chronic inflammatory state in the local tissues, accounting for the diverse symptoms

- Interferon $\alpha$ and $\gamma$ act synergistically against enterovirus in vitro, and preliminary studies suggest that this combination may be an effective treatment for patients with chronic enteroviral infection

Self replicating double stranded RNA molecules (replicons) have been well studied and are currently used as vectors for DNA vaccines and drug susceptibility assays. ${ }^{55}$ Double stranded RNAs can be extremely potent adjuvants for immune responses or, alternatively, these molecules with certain sequences may silence our genes by blocking our mRNA, ${ }^{57}$ although the evidence for this last mechanism is not yet available for CFS.

"Ironically, the continuing inflammatory response towards persistently infected cells/tissues to halt viral infection may be partially responsible for the difficulty in finding viral genomes in these patients, and may also be responsible for the symptoms"

The paradox remains, however, that despite an ongoing immune response, these viral RNA infected cells are not eradicated. It is possible that viruses hide in long living, immunologically privileged cells, including but not limited to, macrophages, muscles, myocardial cells, and neurones, ${ }^{28-37}$ although these cells are unable to produce much live viruses, perhaps, in part, because of the pressure from local interferon and high concentrations of neutralising antibody-a form of cryptic infection. Viral antigen has been identified in tissues by virus specific monoclonal antibodies but positive staining did not allow the differentiation between membrane bound viral proteins and sequestered virions. ${ }^{58}{ }^{59}$ Persistent infection of $\mathrm{B}$ cells and monocytes/macrophages, the cells initially responsible for the uptake/transport of virus, has been well described for other intracellular pathogens. ${ }^{60}$ Recently, we have found enteroviral RNA in the bone marrow samples of two patients with CFS and cyclic neutropenia (JK Chia, unpublished observation, 2004), suggesting that stem cells in the bone marrow could be a source of ongoing viral infection, as reported in animal models of enteroviral infection. ${ }^{59}$ 
Thus, renewed interest is needed to study further the role of enterovirus as the causative agent of CFS. Many aspects of this research need to be addressed but there are three urgent priorities. (1) To overcome the technical difficulties associated with the enteroviral RNA detection assay, because a reliable and reproducible measurement of cell associated viral RNA will provide a marker for antiviral treatment and provide conclusive evidence of chronic infection. (2) To perform a proof of concept, randomised, double blinded, placebo controlled clinical trial investigating the efficacy of the combination of interferon $\alpha$ and $\gamma$. (3) To develop inhibitors for viral RNA replicase, the main mechanism for RNA replication, which allows the persistence of the viral genome in infected cells. In the future, a well designed, randomised, controlled trial of antiviral treatment will ultimately provide crucial information on the pathogenic role of enterovirus in patients with CFS and other chronic diseases.

\section{ACKNOWLEDGEMENT}

The laboratory work was supported by the Chu-Lee Tu memorial research fund.

\section{REFERENCES}

1 Fukuda K, Straus SE, Hickie I, et al. The chronic fatigue syndrome: a comprehensive approach to its definition and study. Ann Intern Med 1994;121:953-9.

2 Reeves WC, Lloyd A, Vernon SD, et al. Identification of ambiguities in the 1994 chronic fatigue syndrome research case definition and recommendations for resolution. BMC Health Serv Res 2003;3:25-9.

3 Komaroff AL, Gupta S, Salit IE. Post-viral fatigue syndrome. In: Ablashi DV, Faggioni A, Keiger GRF, et al, eds. Epstein-Barr virus and human disease 1988. Clifton, New Jersey: Humana Press, 1989:235-53.

4 Levy JA. Viral studies of chronic fatigue syndrome: introduction. Clin Infect Dis 1994;18(suppl 1):S117-22.

5 Chia JKS, Chia LY. Chronic Chlamydia pneumoniae infection, a treatable cause of chronic fatigue syndrome. Clin Infect Dis 1999;29:452-3.

6 Lerner MA, Zervos M, Dworkin HJ, et al. New cardiomyopathy: pilot study of intravenous ganciclovir in a subset of chronic fatigue syndrome. Infect Dis Clin Pract 1997;6:110-17.

7 Kerr JR, Cunniffe VS, Kelleher $P$, et al. Successful intravenous immunoglobulin therapy in 3 cases of parvovirus B19-associated chronic fatigue syndrome. Clin Infect Dis 2003;36:e100-6.

8 Chia JKS, Jackson B. Myocarditis due to parvovirus B19 in an adult patient. Clin Infect Dis 1996;23:200-1.

9 Chia JK, Chia A. Diverse etiologies for the chronic fatigue syndrome. Clin Infect Dis 2003;36:671-2.

10 Yousef GE, Mann GF, Smith DF, et al. Chronic enterovirus infection in patients with postviral fatigue syndrome. Lancet 1988;1:146-7.

11 Landay AL, Jessop C, Lennette ET, et al. Chronic fatigue syndrome: clinical condition associated with immune activation. Lancet 1991;338:707-12.

12 Miller NA, Carmichael HA, Calder BD, et al. Antibody to coxsackie B virus in diagnosing post-viral fatigue syndrome. BMJ 1991;302:140-3.

13 HalpinD, Wessely S. VP1 antigen in chronic postviral fatigue syndrome [letter]. Lancet 1989;1:1028-9.

14 Manian FA. Simultaneous measurement of antibodies to Epstein-Barr virus, human herpesvirus 6 , herpes simplex virus type 1 and 2 , and 14 enteroviruses in chronic fatigue syndrome: is there evidence of activation of a nonspecific polyclonal immune response. Clin Infect Dis 1994;19:448-53.

15 Swanink CM, Melchers WJ, van der Meer JW, et al. Enterovirus and the chronic fatigue syndrome. Clin Infect Dis 1994;19:860-4.

16 Minor PD, Bell EJ. Picornaviridae. In: Collier LH, Timbury MC, eds. Principles of bacteriology, virology and immunology, 8th ed. London: Arnold Publisher, 1990:323-56.

17 Nairn C, Galbraith DN, Clements GB. Comparison of coxsackie B neutralization and enteroviral PCR in chronic fatigue patients. J Med Virol 1995;46:310-13.

18 Behan PO, Behan WMH, Bell EJ. The post-viral fatigue syndrome-an analysis of the findings in 50 cases. J Infect 1985;10:211-22.

19 Gow JW, Behan WMH, Clements GB, et al. Enteroviral RNA sequences detected by polymerase chain reaction in muscle of patients with post-viral fatigue syndrome. BMJ 1991;302:692-6.

20 Gow JW, Behan WMH, Simpson K, et al. Studies on enterovirus in patients with chronic fatigue syndrome. Clin Infect Dis 1994;18(suppl):S126-9.

21 Yousef GE, Isenberg DA, Mowbray JF. Detection of enteroviral-specific RNA sequence in muscle biopsy specimens from patients with adult-onset myositis. Ann Rheum Dis 1990;49:310-15.

22 Cunningham L, Bowles NE, Lane RJM, et al. Persistence of enteroviral RNA in chronic fatigue syndrome is associated with abnormal production of equal amounts of positive and negative strands of enteroviral RNA. J Gen Virol 1990:71:1399-402.

23 Galbraith DN, Nairn C, Clements GB. Phylogenetic analysis of short enteroviral sequences from patients with chronic fatigue syndrome. J Gen Virol 1995;76:1701-7.
24 McArdle A, McArdle F, Jackson MJ, et al. Investigation by polymerase chain reaction of enteroviral infection in patients with chronic fatigue syndrome. Clin Sci 1996;90:295-300.

25 Lindh G, Samuelson A, Hedlund KO, et al. No finding of enteroviruses in Swedish patients with chronic fatigue syndrome. Scand J Infect Dis 1996;28:305-7.

26 Lane RJ, Soteriou BA, Zhang $\mathrm{H}$, et al. Enterovirus related metabolic myopathy: a postviral fatigue syndrome. I Neurol Neurosurg Psychiatry 2003:74:1382-6.

27 Douche-Aourik F, Berlier W, Feasson L, et al. Detection of enterovirus to human skeletal muscle from patients with chronic inflammatory muscle disease or fibromyalgia and healthy subjects. J Med Virol 2003;71:540-7.

28 Walker DL. Persistent viral infection in cell cultures. In: Sanders M, Lennette EH, eds. Medical and applied virology. St Louis: WH Green, 1968:99-110.

29 Argo E, Gimenez B, Cash P. Non-cytopathic infection of rhabdomyosarcoma cells by coxsackie B5 virus. Arch Virol 1992;126:215-29.

30 Tonew M, Hartmann M, Schmidtke M, et al. Replication and persistence of coxsackieviruses B3 in human fibroblasts. Int J Med Microbiol Virol Parasitol Infect Dis 1995;282:92-101.

31 Harrath R, Bourlet T, Delezay O, et al. Coxsackievirus B3 replication and persistence in intestinal cells from mice infected orally and in the human $\mathrm{CaCo}$ 2 cell line. J Med Virol 2004;74:283-90.

32 Zanone MM, Favaro E, Conaldi PG, et al. Persistent infection of human microvascular endothelial cells by coxsackie $B$ viruses induces increased expression of adhesion molecules. J Immunol 2003;171:438-46.

33 Yin H, Berg AK, Westman J, et al. Complete nucleotide sequence of a coxsackievirus B-4 strain capable of establishing persistent infection in human pancreatic islet cells: effects on insulin release, proinsulin synthesis, and cell morphology. J Med Virol 2002;68:544-57.

34 Brilot F, Chehadeh W, Charlet-Renard C, et al. Persistent infection of human thymic epithelial cells by coxsackievirus B4. J Virol 2002;76:5260-5.

35 Feuer R, Mena I, Pagarigan R, et al. Cell cycle status affects coxsackievirus replication, persistence, and reactivation in vitro. $J$ Virol 2002;76:4430-40

36 Vuorinen T, Vainionpaa R, Heino J, et al. Enterovirus receptors and virus replication in human leucocytes. J Gen Virol 1999;80:921-7.

37 Dagan R, Menegus MA. Replication of enteroviruses in human mononuclear cells. Isr J Med Sci 1992;28:369-72.

38 Tam PE, Messner RP. Molecular mechanisms of coxsackievirus persistence in chronic inflammatory myopathy: viral RNA persists through formation of a double-stranded complex without associated genomic mutations or evolution. J Virol 1999;73:10113-21.

39 Reetoo KN, Osman SA, Illavia SJ, et al. Quantitative analysis of viral RNA kinetics in coxsackievirus B3-induced murine myocarditis: biphasic pattern of clearance following acute infection, with persistence of residual viral RNA throughout and beyond the inflammatory phase of disease. J Gen Virol 2000;81:2755-62.

40 Klingel K, Stephan S, Sauter $M$, et al. Pathogenesis of murine enterovirus myocarditis: virus dissemination and immune cell targets. J Virol 1996;70:8888-95.

41 Koelle DM, Barcywell J, Laing I, et al. Markers of viral infection in monozygotic twins discordant for chronic fatigue syndrome. Clin Infect Dis 2002;35:518-25.

42 Chia JK, Jou NS, Majera L, et al. The presence of enteroviral RNA (EV RNA) in peripheral blood mononuclear cells (PBMC) of patients with the chronic fatigue syndrome (CFS) associated with high levels of neutralizing antibodies to enteroviruses [abstract 405]. Clin Infect Dis 2001;33:1157.

43 Rotbart HA, Levin MJ, Murphy NL, et al. RNA target loss during solid phase hybridization of body fluids-quantitative study. Mol Cell Probes 1987; 1:347-58.

44 Heim A, Grumbach I, Pring-Akerblom P, et al. Inhibition of coxsackievirus B3 carrier state infection of cultured human myocardial fibroblasts by ribavirin and human natural interferon-alpha. Antiviral Res 1997;34:101-11.

45 Matsumori A, Wang $\mathrm{H}$, Abelmann WH, et al. Treatment of viral myocarditis with ribavirin in an animal preparation. Circulation 1985;71:843-39.

46 Kishimoto C, Crumpacker CS, Abelmann WH. Ribavirin treatment of murine coxsackievirus $B_{3}$ myocarditis with analyses of lymphocyte subsets. J Am Coll Cardiol 1988; 12:1334-41

47 Brook MG, Bannister BA, Weir WRC. Interferon-alpha therapy for patients with chronic fatigue syndrome. J Infect Dis 1993;168:791-2.

48 See DM, Tilles JG. Alpha interferon treatment of patients with chronic fatigue syndrome. Immunol Invest 1996;25:153-64.

49 Chia J, Chia A. Ribavirin and interferon $\alpha$ for the treatment of patients with chronic fatigue syndrome associated with chronic coxsackievirus B infection: a preliminary observation. J Appl Res 2004;4:286-92.

50 Heim A. Recombinant interferons beta and gamma have a higher antiviral activity than interferon-alpha in coxsackievirus B3-infected carrier state cultures of human myocardial fibroblasts. J Interferon Cytokine Res 1996;16:283-7.

51 Couderc T, Girard S, Pelletier I, et al. Inhibition of poliovirus RNA synthesis as a molecular mechanism contributing to viral persistence in the mouse central nervous system. Dev Biol (Basel), 2001;105:225-30.

52 Triantafyllopoulou A, Tapinos N, Moutsopoulos H. Evidence for coxsackievirus infection in primary Sjogren's syndrome. Arthritis Rheum 2004;50:2897-902

53 Suhadolnik RJ, Reichenback NL, Kitzges P, et al. Upregulation of the 205A synthetase/RNase $\mathrm{L}$ antiviral pathway associated with chronic fatigue sydrome. Clin Infect Dis 1994;18:S96-104.

54 Vojdani A, Choppa PC, Lapp CW. Downregulation of RNase L inhibitor correlates with upregulation of interferon-induced proteins (2-5A synthetase 
and RNase L) in patients with chronic fatigue immune dysfuntion syndrome. I Clin Lab Immunol 1998;50:1-16.

55 Khromykh AA. Replicon-based vectors of positive strand RNA viruses. Curr Opin Mol Ther 2000;2:555-69.

56 Sumpter R Jr, Wang C, Foy E, et al. Viral evolution and interferon resistance of hepatitis C virus RNA replication in a cell culture model. J Virol 2004;78:11591-604.

57 Meister G, Tuschl T. Mechanisms of gene silencing by double-stranded RNA. Nature 2004;431:343-9.
58 Li Y, Boulet T, Andreoletti L, et al. Enteroviral capsid protein VP1 is present in myocardial tissue from some patients with myocarditis or dilated cardiomyopathy. Circulation 2000;101:231-4.

59 Feuer R, Mena I, Pagarigan RR, et al. Coxsackievirus B3 and the neonatal CNS: the roles of stem cells, developing neurons, and apoptosis in infection, viral dissemination, and disease. Am J Pathol 2003;163:1379-93.

60 Johnston RB Jr. Monocytes and macrophages. N Engl J Med 1988; $318: 747-52$

\section{THE LIGHTER SIDE}

\section{The world is not enough}

Doctor, I've been having a headache ever since I left my man,

Do not worry, you're in good hands, lets get a CT scan.

Will it take my headache away?

No, but it'll give me a day.

And about my sensation of burning,

Our GI endoscopist will cure your tossing and turning.

No doc, it's not my stomach but the urinary bladder,

To scope you there our urologist will be gladder.

I also have gas that turns me around,

For these things, we have the ultrasound.

Don't know if I should mention about the watering of my right eye,

Extremely good resolution of that area with the MRI.

At my age, should I worry about my urea, sugar and cholesterol,

Just give us some blood and we'll sort them all.

These tests are going to cost me the world,

The sight of the bill makes me choke makes me cough,

Think what you want dear lady, these days

The world is not enough!

\section{N Kakkar}

